\title{
Relating Personality Traits as Predictors of Work- Family Conflict among Hospital Workforce
}

\author{
Bede Chinonye Akpunne ", Francis C Uzonwanne, Joshua Oludare Ogunsemi, Abayomi Olubanjo Olusa \\ Department of Behavioural Studies, Faculty of Social Sciences, Redeemers' University, Ede, Osun State, Nigeria
}

Correspondence: Bede Chinonye Akpunne; akpunneb@ run.edu.ng

Received 24 August 2020;

Accepted 12 September 2020;

Published 16 September 2020

\begin{abstract}
The work pressure of health personnel has remained a challenge ravaging the efficiency of their indispensable roles in saving other lives and their satisfaction with the management of their own family lives. This study related possible linkages between personality traits and work family conflicts among health personnel. A cross sectional survey design was adopted and 260 (male 116 (44.4\%) and female 144 (55.6\%)) from six state owned hospitals were randomly selected to participate in this study. They responded to Big Five Inventory (BFI) and Work Family Conflict Scale, both of which are standardized instruments. Four hypotheses were tested and the structural equation model (SEM) with AMOS 26 results revealed a significant positive relationship between work-family conflict and neuroticism. Work-family conflict was negatively linked with openness and agreeableness. Neuroticism $(\beta=0.320, \mathrm{CR}=5.355, \mathrm{p}<0.001)$ and openness $(\beta=-0.125, \mathrm{CR}=-2.111, \mathrm{p}<0.05)$ significantly predicted work-family conflict positively and negatively respectively. All the personality traits jointly explained $12 \%$ variance in work-family conflict. Age was not found to significantly predict work-family conflict. SPSS 23 results showed a statistically significant reliable difference between the mean scores of the work-family conflict of doctors compared with nurses [ $\mathrm{t}(258)=2.58, \mathrm{p}<.05]$. The implications of the findings are discussed in line with family focused hospital management policies.
\end{abstract}

Keywords: Personality traits, work-family conflict, hospital workforce, Doctors, Nurses.

\section{Introduction}

The responsibilities of life savers are one of those that never go to sleep. Medical and auxiliary employees alike are known to work round the clock, even in laid back towns where civil servants, business owners and employees typically close shop before dusk. The fact that the business of life saving never sleeps, keeps a lot of life savers and their ancillary staff working beyond the expected hours and/or odd epoch shifts most times. These medical and auxiliary employees, as is expected, also have their private family lives which they have to nourish. The management of family, being the foundational structure of any society, must not be taken with kids' gloves. It is important to balance the experience of work and family adequately. The work-family conflict of these life savers is the focus of this study. State owned hospitals in Northern Nigeria, where this study was carried out, offer the most affordable and available medical services in the country. The part of the country where this study is carried out also reports poverty in epic amounts [1]. The implication is that most state hospital employees will possibly experience worked overload and underpaid for their extra efforts. This is likely to affect their work family experience in many ways that is readily known.

Work and family remain two critical areas of life in general as most adults rotate around these two concentrations. Managing the demands of work and family is a persistent challenge among adults in general and medical and auxiliary employees specifically. All employees must balance the needs of their work and non-work lives as adequately as possible, to maintain psychological balance. Despite significant advances in the work-family literature; two essential gaps in general knowledge exists. Firstly, how individual differences that affect the way people balance work and family domains have been disregarded ${ }^{[2]}$. Secondly, few investigations and studies have pointed out the possibility that work and family roles can have a positive impact on one another ${ }^{[3]}$. Work-related factors are work demand, work-conflict, and supervisor support; and family-related factors are family demand, family-conflict, and family support. However, researchers in the last one decade have argued that individual differences that structure the personality of persons such as extraversion, conscientiousness, agreeableness, neuroticism, and openness to experience affects work and family experience $^{[4]}$.

Personality refers to the constant perception and processes that influence people's interpretation and reaction, emotionally, and behaviorally to their surroundings ${ }^{[5]}$. The characteristics of personality determine individual differences. Scholars approve that virtually all personality measures could be categorized according to the five-factor model of personality (also referred to as the "big five" personality dimensions) ${ }^{[6]}$. However, the fundamental aspects of the five factors have been shown to include hundreds of personality traits suggested by researchers to define unique 
differences in behavior ${ }^{[7]}$. Thus, the big five factors seem appropriate for capturing a broad picture of individual personality and their behavioral patterns and interpretation of actual situations in a variety of life domains ${ }^{[8]}$. Personality can also be defined as a dynamic or set of characteristics possessed by a person that influence cognition, motivation, and behavior in a variety of situation. The term personality is often used in informal conversations. Its meaning is broad, and in general, it is mostly used to describe a person's social attractiveness ${ }^{[9]}$. Ryckman ${ }^{[9]}$ stated that a lot of definitions exist for the term personality, which is all quite different in nature. He also opines that "personality is the dynamic and organized set of characteristics that distinctively influences his or her perceptions, motivations, and behaviors in various situations". This definition by implication means that personality describes the very foundation of human individuality. Not every individual difference is a difference in personality. Ozer and Benet ${ }^{[10]}$, affirm that personality is a useful tool that predicts job performance. This is because the way people resolve complications and how well they perform, and complete tasks will contribute to the organization achievement. As a result, this will reflect on effective job performance.

The big five personality measurement are five broad domains of personality that were utilized to depict human identity. They are 1) Extraversion: Kind of people who are typically dynamic, self-assured, lively, eager, cordial, and chatty ${ }^{[11]} .2$ ) Agreeableness: Helpful persons, amiability, excusing, kind, compassion toward others, warm and trusting for the most part ${ }^{[11]}$. 3) Conscientiousness: Persons who are capable, composed, achievement-oriented, dependable, maintains orderliness, efficient, thoroughness and hardworking; these kinds of persons, for the most part, have elevated requirements and endeavor to accomplish objectives ${ }^{[8,11]}$. 4) Neuroticism: Individuals experience passionate precariousness like uneasiness, instability, touchiness, protectiveness, pressure, stress, and misery ${ }^{[12]}$. 5) Openness to experience: Persons with this attribute show insight, unusualness, creative energy, interest, inventiveness, and innovation ${ }^{[8,11]}$. Duckworth and Yeager ${ }^{[13]}$ stated that a personality profile include tools that can be used to provide an evaluation of an employee's attributes, values, and life skills to maximize his or her job performance and contribution to the company.

Work-family struggle happens when the requests from work and family are irreconcilable ${ }^{[14,15]}$. Greenhaus and Beutell ${ }^{[15]}$ further stratified work-family conflict into three forms: (a) timebased, (b) strain-based, and (c) behavior-based conflicts. Timebased conflict alludes to covering plans with weights among work and family jobs, because it might be challenging to be both physically and mentally present within both roles ${ }^{[15]}$. Strain-based conflict alludes to work and family related stressors that produce mental and enthusiastic strain because the requests of other life spaces are hard to satisfy ${ }^{[15]}$. Behavior-based conflict alludes to various social desires inside work and family spaces and the failure to alter one's conduct as indicated by these desires inside every life area ${ }^{[15,16]}$.

In recent times, there is generally little research that has been done to encourage the comprehension of individual contrasts that impact work-family involvement ${ }^{[17]}$. Besides, as of late researchers have required a closer examination of the connection between personality characteristics and work-family conflict ${ }^{[17]}$. In this study, personality as a factor in balancing work and family conflict experience is investigated. What is the relationship between personality traits (agreeableness, extraversion, conscientiousness, resourcefulness, and emotional stability), worklife experience (negative work-home interaction, positive workhome interaction, negative home-work interaction, and positive home-work interaction)? Can personality traits be used to predict work-family conflict? These are the major research concerns of this study. In a larger picture, this research seeks to determine whether the personalities of medical and auxiliary personnel work and family experiences are either balanced or overlapping.

This study examines the correlates of the big five personality traits on work-family conflict among medical and auxiliary personnel of State-owned hospitals in Kano Metropolis, Nigeria. The study is geared towards the following specified objectives which are to.

1. Determine the relationship between the personality types; Openness, Extraversion, Agreeableness, Conscientious and Neuroticism and work-family conflict.

2. Investigate the joint relationship between age and personality traits and work-family conflict.

3. Examine age as a predictor of work-family conflict.

4. Observe the difference in work-family conflict between occupation type (Doctors and Nurses) among medical and auxiliary personnel.

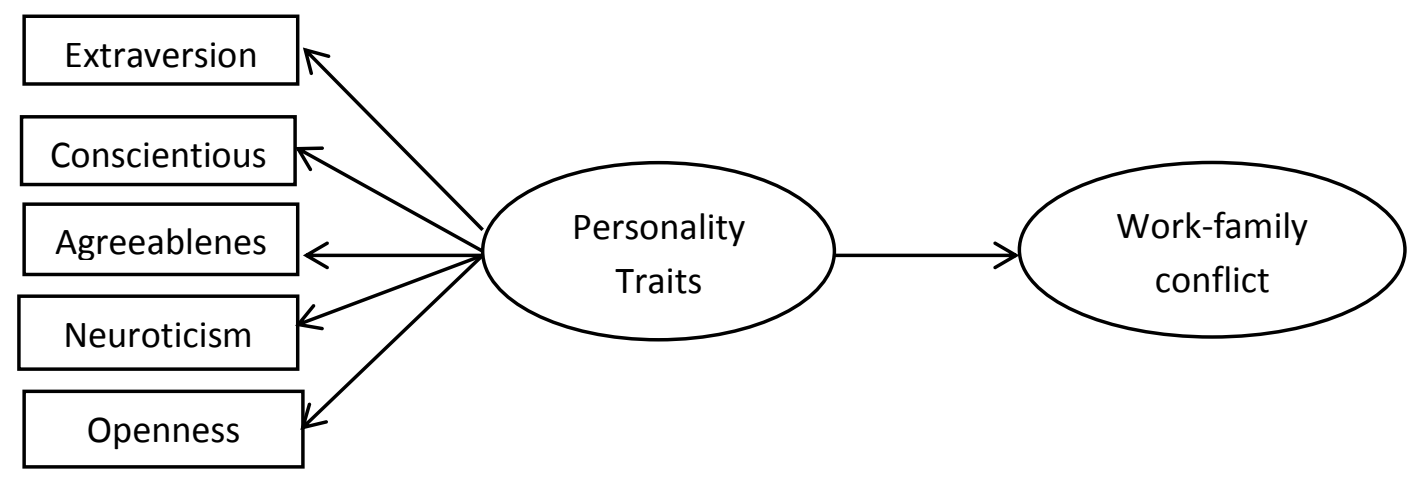

Figure 1: Conceptual Framework of Work-family conflict and Personality traits

\section{Hypotheses of the Study}

1. Personality traits: Openness, Extraversion, Agreeableness, Conscientious and Neuroticism will singly and significantly predict work-family conflict.

2. Personality traits and age will jointly and significantly predict work-family conflict.
3. Age of employees will significantly predict work-family conflict.

4. There will be a significant difference in work-family conflict between occupation type (Doctors and Nurses) among medical and auxiliary personnel. 


\section{Materials and Methods}

\section{Design}

A cross sectional survey research design was adopted to examine the predictive influence of the big five personality trait on the work-family conflict of medical and auxiliary personnel in selected State-owned hospitals in Kano Metropolis, Nigeria. The independent variable is the big five personality trait, while the dependent variable is the work-family conflict.

\section{Participants}

A total of 260 participants were selected using random sampling technique from the corporate workforce in the hospital organizations. Sociodemographic characteristics show that 116 (44.4\%) of total participants were male while 144 (55.6\%) were females. The age of participants ranges from twenty-two to fiftynine years with a mean of 34.05 and standard deviation of 8.95 . Also, participants relationship status revealed that 62 (23.8\%) of the participants were doctors while 198 (76.2\%) participants were nurses.

\section{Instruments}

A test comprising of two psychological tests and a section for demographic data was used for data collection, the psychological tests are stated below.

The Big Five Inventory (BFI) John \& Srivastava ${ }^{[18]}$ : It comprises of 44 items meant to measure the five personality dimensions; Extraversion (items 1- 8), Agreeableness (items 9 - 17), Conscientiousness (items 18 - 26), Neuroticism (items 27 - 34) and Openness (items 35 - 44).

Openness to experience focuses on an individual's degree of curiosity, conscientiousness focuses on the degree of flexibility, extraversion focuses on the degree of sociability, agreeableness focuses on the degree of cooperation towards others, while neuroticism focuses on the degree of vulnerability to psychological stress. The scale was measured on a likert format ranging from 1Disagree Strongly to 5- Agree strongly. Reliability coefficient (Cronbach's Alpha) for each factor of the personality traits was
0.779 (openness to experience), 0.727 (conscientiousness), 0.725 (extraversion) and 0.716 (neuroticism). Since all the reliability coefficients exceeded the minimum value of 0.7 , the measures were considered consistent and reliable for the study. The instrument also has acceptable validity records. Scores equal to or higher than the norms on each of the dimensions indicated that the individual manifest the specific personality type while scores lower indicate otherwise.

Work to Family and Family to Work Conflict Scale by Netemeyer $\&$ McMurrian ${ }^{[19]}$ : It comprises of 5 items for each construct that measures inter-role conflict between work and family. This scales response technique uses the 1 to 7 Likert scale type; Responses range from 1 (strongly disagree) to 7 (strongly agree). Pearson reliability coefficient of the first sub-dimension which is workfamily conflict was .90 , while the reliability of the second subdimension which is family-work conflict was .89. The $\mathrm{H}$ coefficient ranges from $0-1$ with the values above .70 indicating very good internal consistency of the measure. The coefficient alpha for the Work-Family conflict scale was .92, while the alpha for the Family-Work Conflict scale was .79. Acceptable validity is also reported for this instrument. High scores specify high levels of work/family conflict.

\section{Results}

Pearson's correlation in Table 1 was used to check for the relationship among the age, work-family conflict, openness extraversion, agreeableness, conscientiousness, and neuroticism. Knowledge of the relationships of these variables led to betterrounded conclusions about the predictive ability of age, openness extraversion, agreeableness, conscientiousness, and neuroticism on work-family conflict. The result of the zero-order correlation shows that there was a significant positive relationship between work-family conflict and neuroticism $[\mathrm{r}(258)=.33, \mathrm{p}<.01]$. However, work-family conflict had a significant negative relationship with openness to experience $[\mathrm{r}(258)=-.14, \mathrm{p}<.05]$ and agreeableness $[\mathrm{r}(258)=-.21, \mathrm{p}<.01]$.

Table 1: Means, Standard Deviations and Zero Order Correlation of Variables

\begin{tabular}{|l|l|l|l|l|l|l|l|}
\hline Variables & 1 & 2 & 3 & 4 & 5 & 6 & 7 \\
\hline 1. Age & - & & & & & \\
\hline 2. Openness & .01 & - & & & & \\
\hline 3. Extraversion & .10 & $.17^{* *}$ & - & & & \\
\hline 4. Agreeableness & .09 & $.37^{* *}$ & .11 & - & & & \\
\hline 5. Conscientiousness & $.25^{* *}$ & $.14^{*}$ & $.16^{* *}$ & $.37^{* *}$ & - & & \\
\hline 6. Neuroticism & $-.13^{*}$ & -.05 & -.07 & $-.48^{* *}$ & $-.33^{* *}$ & - & \\
\hline 7. Work-family Conflict & -.02 & $-.14^{*}$ & -.03 & $-.21^{* *}$ & -.10 & & \\
\hline Mean & 34.05 & 34.43 & 24.83 & 36.09 & 31.13 & 19.71 & - \\
\hline Standard Deviation & 8.95 & 5.52 & 4.76 & 5.89 & 4.82 & 5.77 & 12.11 \\
\hline
\end{tabular}

Note: $* * p<.01, * p<.05, N=260$

\section{Structural Model}

To test the hypothesized structural model, it is hypothesized that openness, extraversion, agreeableness, conscientiousness, and neuroticism will significantly predict work-family conflict among employees in the health sector. The model in Figure 2 revealed a good and acceptable fit; $\left.X^{2}(24.621)=8.879, \mathrm{p}<0.05(0.006)\right\}$; $\mathrm{CFI}=0.368$, TLI $=-0.966$, RMSEA $=0.231$. This shows that the model indices fit is above the acceptable threshold. Results of the first hypothesis show that two of the personality traits; neuroticism $(\beta=0.320, \mathrm{CR}=5.355, \mathrm{P}<0.001\{0.000\})$ and openness $(\{\beta=$ -
$0.125, \mathrm{CR}=-2.111, \mathrm{P}<0.05\{0.035\})$ significantly predicted workfamily conflict. This partially supported the first hypothesis. The second hypothesis, which stated that age and personality traits will jointly significantly predict work-family conflict was confirmed. It was found that all the personality traits jointly explain $12 \%$ variance in work-family conflict, thus, indicating a joint prediction. Testing the third hypothesis showed that age was not a significant predictor of work-family conflict $(\beta=0.018, \mathrm{CR}=0.303, \mathrm{P}>$ $0.05\{0.762\})$. 


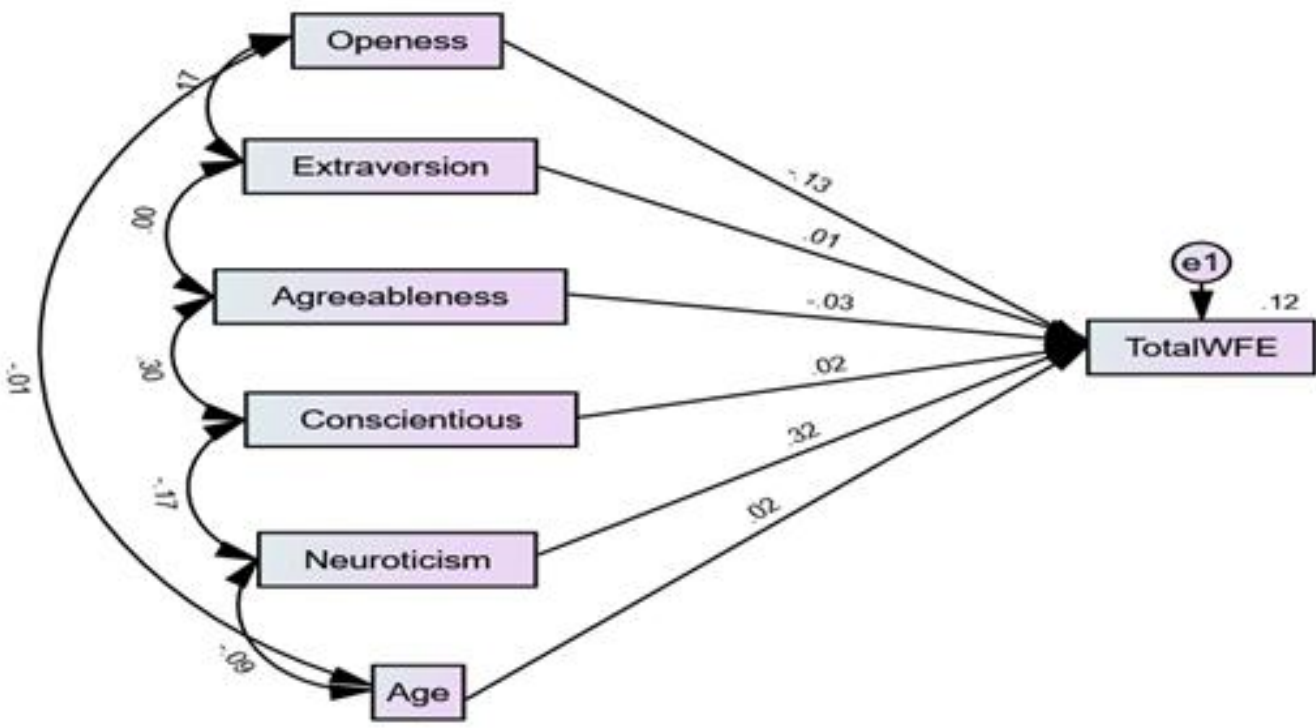

Figure 2: Regression Model of personality traits of medical personnel on work-family conflicts

Table 2: Independent t-Test showing Work-family Conflict Scores Based on Occupational Type

\begin{tabular}{|c|c|c|c|c|c|c|c|}
\hline & Occupation & $\mathrm{N}$ & Mean & $\mathrm{SD}$ & $\mathrm{df}$ & $\mathrm{t}$ & $\mathrm{p}$ \\
\hline \multirow{2}{*}{ Work-Family Conflict } & Doctors & 62 & 19.26 & 7.51 & 258 & 2.58 & $<.05$ \\
\cline { 2 - 9 } & Nurses & 198 & 16.22 & 8.10 & & & \\
\hline
\end{tabular}

The fourth hypothesis which states that there will be a significant difference in the work-family conflict among the medical personnel based on occupation type (doctors and nurses) was confirmed. The result indicated a statistically significantly reliable difference between the mean of the work-family conflict scores that the doctors had $(\mathrm{M}=19.26, \mathrm{SD}=7.51)$ and that of the nurses $(\mathrm{M}=16.22, \mathrm{SD}=8.10),[\mathrm{t}(258)=2.58, \mathrm{p}<.05]$. It can be therefore concluded that the work-family conflict experienced by doctors was higher than that of nurses.

\section{Discussion}

The outcome from hypothesis one, two and three, which examined age and the personality types, openness, extraversion, agreeableness, conscientious and neuroticism as joint and single significant predictors of work-family conflict among medical personnel of state owned hospitals in Kano Metropolis showed that age and the personality types jointly accounted for $12 \%$ of the total variation in work-family conflict. Analysis also revealed that two out of the five personality types predict work-family conflict: openness and neuroticism. Age, singled out was not a significant predictor of work-family conflict. The results taken together indicate that personality types significantly predict work-family conflict. This result is somewhat consistent with existing literature surrounding the variables of study. Malekiha, Mohammed and Iran ${ }^{[4]}$, found that extraversion was not related to work-family conflict, whereas neuroticism was related to work-family conflict, accounting for $15 \%$ variance in work-family conflict. Agreeableness and conscientiousness were both unique negative predictors of work-family conflict ${ }^{[4]}$. Priyadharshini and Wesley ${ }^{[20]}$ however used a structural equation regression modeling to predict work-family conflict by the personality dimensions. Results suggest that the personality dimensions such as extraversion, conscientiousness, openness to experience, and agreeableness predict Work-family conflict. Neuroticism did not appear to support their findings ${ }^{[20]}$. In spite of some inconsistencies in the literature, several researchers had reported significant association between neuroticism and work-family conflict ${ }^{[17,21]}$. Age also did not prove to be a significant predictor of work-family conflict when analyzed singly. This finding is also somewhat consistent with existing literature. In Thrasher, Wynne, Bramble and Baltes ${ }^{[22]}$ study, their results support the inverted $U$ relationship between age and work-life conflict, with this effect being moderated by gender. When examined separately, there is a prominent inverted $\mathrm{U}$ relationship between age and work-life conflict for men, while the relationship is linear and negative for women ${ }^{[22]}$. The result of the fourth hypothesis revealed a statistically significantly reliable difference between the experiences of work-family conflict by doctors compared to that of nurses. Explaining this, the workfamily conflict of the doctors was higher than that of the nurses. Literatures surrounding the variables of the fourth hypothesis are scarce and presumed as either not available or not easily assessable. It is hoped that this finding will reflect in literature surrounding the variables of study.

\section{Conclusions and Recommendations}

Among the medical personnel, work-family conflict is positively related with neuroticism, but negatively linked openness and agreeableness. Neuroticism is a significant positive predictor while openness is a significant negative predictor of work-family conflict among the participants. Again, age is not a significant predictor of work-family conflict among the medical personnel. Lastly, the work-family conflict experienced by doctors was higher than that of nurses.

Recruiting and human resources departments of hospitals should encourage the inclusion of personality assessments with trained interpretation in their recruiting and placement procedures to identify training or counseling needs for their staff. Inability to manage work-family conflicts can be detrimental to the 
management of medical units. Hospital management should endeavor to organize the training of medical workers in communication skills and interpersonal skills that could enhance work and family life in general. Management should put in place various family-friendly policies in line with government legislation to increase employees' positive experience at work and at home.

\section{Limitation of Study}

This study was carried out in just one northern state of Nigeria, Kano Metropolis. The study also covered only state-owned general hospitals. To this population and geographical setting therefore, the ability to generalize findings is limited. Future study can consider a larger population including other hospital types like psychiatric hospitals and privately owned hospitals in the bid to enrich the body of knowledge.

\section{Ethics approval and consent to participate}

This study was only supported and carried out by the financial contributions of the authors/researchers listed on this article. All procedures performed in this study involving human participants were in accordance with the ethical standards of the institutional research committee and with the 1964 Helsinki Declaration and its later amendments. Informed consent was obtained from all individual participants involved in the study.

\section{Conflicts of Interest}

The authors declare that they have no conflicts of interest concerning this study.

\section{List of abbreviations}

BFI Big Five Inventory

SEM Structural Equation Model

RMSEA Root Mean Square Error of Approximation

CFI Comparative Fit Index

TLI Tucker-Lewis Index

\section{Funding Statement}

This research did not receive any external funding. It was funded solely by the authors.

\section{Authors' contributions}

This work was carried out in collaboration among all authors. BCA designed the study, wrote the first draft and was a major contributor in writing the manuscript. FCU managed the statistical analysis of the study; JOO and AOO managed the literature search and full editing of the manuscript. All authors read and approved the final manuscript.

\section{Acknowledgments}

We acknowledge the management of Redeemer's University, Ede, Osun State Nigeria for the enabling environment provided for us to carry out this research work.

\section{References}

[1] The World Bank. The world bank in Nigeria. Retrieved $20^{\text {th }} \quad$ August $\quad 2020$ from https://www.worldbank.org/en/country/nigeria/overview 2019.

[2] H. C. Sumer, and P. A. Knight, "How do people with different attachment styles balance work and family? A personality perspective on the work-family linkage". Journal of Applied Psychology, 86, 653-663, 2001

[3] J. H. Greenhaus, and S. Parasuraman, "Research on work, family, and gender: Current status and future directions. In G. N. Powell (Ed.), Handbook of gender and work": 391-412. Newbury Park, CA: Sage, 1999

[4] M. Malekiha, R. A. Mohammed, and B. Iran, "Workfamily conflict and personality". Interdisciplinary Journal of Contemporary Research in Business, 3(10). 114-152, 2012

[5] L. R. James and M. D. Mazerolle, "Personality in work organizations". Thousand Oaks, CA: Sage, 2002.

[6] L. R. Goldberg, "The development of markers for the Big-Five Factor structure". Psychological Assessment, 4, 26-42, 1992

[7] W. Fleeson, "Toward a structure and process-integrated view of personality: Traits as density distributions of states". Journal of Personality and Social Psychology, 80, 1011-1027, 2001.

[8] T. A Judge and C. A. Higgins, "The Big Five personality traits, general mental ability, and career success across the life span". Personal Psychology, 52, 621-653, 1999.

[9] R. M. Ryckman, "Theories of Personality". Ninth Edition. USA: Thomson, 2008.

[10] D. J. Ozer, and V. Benet-Martinez, "Personality and the prediction of consequential outcomes". Annual Review of Psychology, 57, 401-421, 2006.

[11] R. R. McCrae, and O. P. John, "An introduction to the five-factor model and its applications". Journal of Personality, 60, 175-215, 1992.

[12] A. Z. Stoeva, R.K. Chiu, and J. H. Greenhaus, "Negative affectivity, role stress, and work-family conflict". Journal of Vocational Behavior, 60, 1-16, 2002.

[13] A. L. Duckworth, and D. S. Yeager, "Measurement matters: assessing personal qualities other than cognitive ability for educational purposes". Ed. Res. 44, 237-251, 2015.

[14] Edwards, J. R., \& Rothbard, D. M. "Complementary and supplementary fit: a theoretical and empirical integration". Journal of Applied Psychology, 89(5), 822$831,2000$.

[15] J. H. Greenhaus, and N. J. Beutell, "Sources of conflict between work and family roles". Academy of Management Review, 10(1), 76-88, 1985.

[16] C. K. Fu, and M. A. Shaffer, "The Tug of work and family: Direct and indirect domain-specific determinants of work-family conflict". Personnel Review, 30, 502$522,2001$.

[17] A. Lin, "The relationship between work/family demands, personality and work-family conflict". The Business Review, 27(1), 272-277, 2013.

[18] O. P. John, and S. Srivastava, "The Big Five Trait taxonomy: History, measurement, and theoretical perspectives". In L. A. Pervin, \& O. P. John. Eds., Handbook of Personality: Theory and Research, Vol. 2, Guilford Press, New York, 102-138, 1999.

[19] R. G Netemeyer, J. S Boles, and R. McMurrian, "Development and validation of work-family conflict 
and family-work conflict scales". Journal of Applied Psychology, 81(4), 400-410, 1996.

[20] R. A. Priyadharshini, and R. J. Wesley, Personality as a determinant of work-family conflict. Journal of Industrial Engineering and Management, 7, 1037-1060, 2014.

[21] C. S. Bruck, and T. D. Allen, "The relationship between big five personality traits, negative affectivity, Type A behavior, and work-family conflict". Journal of Vocational Behaviour, 63, 457-472, 2003.

[22] G. Thrasher, K. Wynne, R. Bramble, and B. Baltes, "Age, work-family conflict, and coping: the moderating role of gender", The Gerontologist, Volume 56, Issue Suppl_3, 1 November 2016, Page 238, 2016. https://doi.org/10.1093/geront/gnw162.948 